\title{
The Regulation of Naphthalene Oxygenase in Pseudomonads
}

\author{
By K. M. SHAMSUZZAMAN AND E. A. BARNSLEY \\ Department of Biochemistry, Memorial University of Newfoundland, \\ St John's, Newfoundland, Canada
}

(Received 2 January 1974; revised 4 February 1974)

S U M M A R Y

Naphthalene oxygenase was induced in several pseudomonads when these were grown on salicylate as a carbon and energy source, or when salicylate was added to cultures growing on succinate. The enzyme was not induced in Pseudomonas strain NCIB9816 when this was grown in the presence of catechol, although after the addition of this compound to cultures growing on succinate the levels of catechol I,2-oxygenase and catechol 2,3-oxygenase were similar to those observed after the addition of salicylate. Furthermore, two structural analogues of salicylate, 2-aminobenzoic acid and 2-hydroxybenzyl alcohol, induced naphthalene oxygenase gratuitously. Therefore salicylate is probably the inducer of naphthalene oxygenase.

\section{INTRODUCTION}

The metabolic pathway by which naphthalene is degraded by certain Pseudomonas species has been reported (Davies \& Evans, I964; Catterall, Murray \& Williams, I97I; Jerina, Daly, Jeffrey \& Gibson, 1971), but the mechanism of the regulation of the initial steps of the pathway has not been elucidated. Azoulay (1966) has reported studies on the simultaneous adaptation of pseudomonads to naphthalene and certain of its degradation products, and from these it might be inferred that either naphthalene or one of its immediate degradation products, but not the later product salicylate, is the inducer of the first enzyme of the pathway, naphthalene oxygenase. We have observed, however, that a number of pseudomonads produce naphthalene oxygenase when grown either on salicylate or on a mixture of salicylate and succinate as carbon and energy sources, and have concluded from studies of the levels of enzymes induced in Pseudomonas strain NCIB9816 under various conditions of growth that salicylate is the inducer of naphthalene oxygenase. This paper reports these observations.

\section{METHODS}

Organisms and culture media. Pseudomonas species able to grow in a mineral medium on naphthalene as a carbon and energy source were obtained from the National Collection of Industrial Bacteria (NCIB8858, NCIB8859, NCIB8860 and NCIB98I6) and from the American Type Culture Collection (ATCCI7483 and ATCCI7484), and three putative pseudomonad strains ( NI, N3 and N4) were isolated locally from different types of soil. These isolates were very short Gram-negative motile rods which oxidized glucose aerobically but not anaerobically, and which gave positive oxidase reactions (Skerman, 1967). For growth on naphthalene this compound, as a solution in ether, was sterilized by filtration into sterile plugged flasks and, after the ether had been allowed to evaporate, sterile mineral salts were added to give a $0 \cdot 1 \%(\mathrm{~W} / \mathrm{v})$ suspension. Freshly prepared sodium salicylate $(0 \cdot 36 \mathrm{M})$ and its analogues were sterilized by filtration, and disodium succinate $(0.85 \mathrm{M})$ was sterilized by autoclaving 
at I $15{ }^{\circ} \mathrm{C}$ for $10 \mathrm{~min}$. The basal mineral medium ( $\mathrm{pH} 6.8$ ) had the final composition $(\mathrm{g} / \mathrm{l})$ : $\mathrm{K}_{2} \mathrm{HPO}_{4}, 4.36 ; \mathrm{NaH}_{2} \mathrm{PO}_{4} . \mathrm{H}_{2} \mathrm{O}, 3.45 ; \mathrm{NH}_{4} \mathrm{Cl}, \mathrm{I} \cdot 0 ; \mathrm{MgSO}_{4} .7 \mathrm{H}_{2} \mathrm{O}, 0.48 ; \mathrm{CaCl}_{2} .2 \mathrm{H}_{2} \mathrm{O}$, $0.036 ;\left(\mathrm{NH}_{4}\right)_{6} \mathrm{Mo}_{7} \mathrm{O}_{24} .4 \mathrm{H}_{2} \mathrm{O}, 0.0002 ; \mathrm{FeSO}_{4} .7 \mathrm{H}_{2} \mathrm{O}, 0.002 ; \mathrm{MnCl}_{2} .4 \mathrm{H}_{2} \mathrm{O}$, 0.00I; $\mathrm{CoCl}_{2}$. $6 \mathrm{H}_{2} \mathrm{O}, 0.00 \mathrm{I}$.

Growth of cultures and preparation of cell extracts. In studies of the effect of salicylate and its analogues on bacteria growing on succinate at $25^{\circ} \mathrm{C}$ in shaken flasks, sterile solutions of the compounds were added during the early exponential phase of growth (apparent absorbance about 0.1 at $600 \mathrm{~nm}$ measured in a Unicam SP800 spectrophotometer) and after the population had doubled about twofold the cells were collected by centrifugation at $2{ }^{\circ} \mathrm{C}$. The pellet was resuspended in ice-cold tris- $\mathrm{HCl}$ buffer $(3 \mathrm{mM}, \mathrm{pH} 7 \cdot 6)$ and sedimented again. The washing was repeated, and the cells were finally suspended at a concentration of about $0.2 \mathrm{~g}$ wet $\mathrm{wt} / \mathrm{ml}$ of tris buffer. Part of the suspension was disrupted with an ultrasonic oscillator (Model WI 85, Heat systems-Ultrasonics, Inc., New York, U.S.A.) at a nominal power of $70 \mathrm{~W}$. A $2 \mathrm{ml}$ portion initially at $0{ }^{\circ} \mathrm{C}$ was subjected to disruption for six halfminute periods. Each period of disruption was followed by 1 min during which the disrupted cells and oscillator probe were cooled in ice water. Particulate matter was then removed from the extract by centrifuging at $105000 \mathrm{~g}$ for $\mathrm{I} \mathrm{h}$ at $4{ }^{\circ} \mathrm{C}$.

Determination of naphthalene oxygenase. Washed cells were resuspended in sodium phosphate buffer $(0.05 \mathrm{M}, \mathrm{pH} 7.0)$ at a maximum absorbance $\left(E_{1 \mathrm{cw}}^{600}\right)$ of 0.19 . Naphthalene in ethanol $(0.02 \mathrm{ml}, 10 \mathrm{~mm})$ was added to $3.0 \mathrm{ml}$ of suspension at $25^{\circ} \mathrm{C}$, and the decrease in absorbance due to naphthalene $\left(E_{1 \mathrm{~cm}}^{276}\right)$ was followed using a Unicam sp80o recording spectrophotometer. The reference cuvette contained bacterial suspension. Under these conditions the initial rate of reaction was directly proportional to the concentration of bacteria. For the calculation of reaction rates an experimentally determined extinction coefficient for naphthalene at $276 \mathrm{~nm}$ of $4.5 \mathrm{I} \mathrm{mM}^{-1} \mathrm{~cm}^{-1}$ was used and the results expressed as $\mu \mathrm{mol}$ naphthalene consumed $/ \mathrm{min} / \mathrm{mg}$ total bacterial protein.

Determination of salicylate hydroxylase and catechol oxygenase. Salicylate hydroxylase was determined by measuring polarographically at $25^{\circ} \mathrm{C}$ the uptake of oxygen in a cell containing tris buffer $(0.03 \mathrm{M}, \mathrm{pH} 7.6)$ and cell free extract (combined volume $\mathrm{I} .4 \mathrm{ml}$, maximum protein concn $0.7 \mathrm{mg} / \mathrm{ml})$, to which NADH $(0.3 \mathrm{ml}, 0.5 \mathrm{~mm})$ and sodium salicylate $(0.3 \mathrm{ml}, 0.4 \mathrm{~mm})$ were added separately. The NADH and salicylate were dissolved in tris buffer. The reported results are corrected for the small NADH oxidase activity remaining in the extract, and were computed assuming a solubility of oxygen in the reaction medium of $0.25 \mathrm{mM}$. Catechol I,2-oxygenase (EC. I. I3.I.I) and catechol 2,3-oxygenase (EC. I.I3.I.2) were measured by the methods of Hegeman (I966) and of Feist \& Hegeman (1969) respectively, except that tris buffer was used in both cases and that catechol was used at concentrations of $0.07 \mathrm{~mm}$ and $0.17 \mathrm{~mm}$ in the respective determinations.

Protein determination. The method of Lowry, Rosebrough, Farr \& Randall (I951) was applied to the insoluble fraction obtained by the treatment of whole cells or cell extracts with trichloracetic acid (final concn $5 \%, \mathrm{w} / \mathrm{v}$ ). Bovine serum albumin was used as a standard.

Identification of salicylate formed from naphthalene during the measurement of naphthalene oxygenase. As soon as the decrease in absorbance at $276 \mathrm{~nm}$ was complete, the reaction mixture was shaken with two half-volumes of ether and this ether extract was discarded. The medium was acidified with $\mathrm{HCl}$ and the extraction was repeated. The combined ether extracts were dried with anhydrous sodium sulphate, filtered, and allowed to evaporate to a small volume at room temperature. Portions of the concentrated ether extract were dissolved in phosphate buffer and the absorption spectrum was measured. Other portions were chromatographed on $0.25 \mathrm{~mm}$-thick layers of silica gel $\mathrm{G}$ with benzene, ether, acetic acid 
and ethanol (I20:60:18: I, by vol.) as developing solvent. When the plates were dry, salicylic acid was detected by its blue fluorescence in u.v. light.

Measurement of the concentration of gratuitous inducers in culture media. Samples of culture medium were withdrawn immediately after the addition of inducer and at intervals thereafter. Each sample was chilled in ice and centrifuged at $2{ }^{\circ} \mathrm{C}$ to remove bacteria. The supernatant was removed, a measured volume diluted accurately and its full absorption spectrum measured. Samples of cultures from which inducer was omitted were treated in a similar way. No material interfering with the measurement of 2-aminobenzoate (at $309 \mathrm{~nm}$ ) or of 2-hydroxybenzyl alcohol (at $273 \mathrm{~nm}$ ) was detected.

\section{RESULTS AND DISCUSSION}

Naphthalene oxygenase activity has been reported in extracts of bacteria grown on naphthalene (Davies \& Evans, I962; Catterall et al. I97I; Catterall \& Williams, 1971). The latter measured the rate of $\mathrm{O}_{2}$ uptake in the presence of $\mathrm{NADH}, \mathrm{Fe}^{2+}$ and reduced glutathione $(\mathrm{GSH})$ by a polarographic method which in our hands proved unreliable. The recovery of naphthalene oxygenase was never more than $5 \%$ of the minimum activity calculated from naphthalene oxidation rates obtained with whole cells, and $\mathrm{O}_{2}$ uptake due to residual NADH oxidase and to the oxidation of $\mathrm{Fe}^{2+}$ and $\mathrm{GSH}$ was much larger than the additional uptake provoked by naphthalene. Whole washed cells of strain NCIB98I 6 were therefore used to measure naphthalene oxygenase by a spectrophotometric method (see Methods). The initial rate of reaction was directly proportional to the concentration of bacteria in the cuvette, up to a maximum $E_{1 \mathrm{~cm}}^{600}$ of about 0.19 . Above this concentration of bacteria, the non-linear response at $276 \mathrm{~nm}$ made it inconvenient to follow naphthalene oxidation in this manner. The apparent $K_{m}$ for naphthalene in the reaction was about $4 \mu \mathrm{M}$. We have noted in unpublished experiments, however, that $\left[{ }^{14} \mathrm{C}\right]$ naphthalene is concentrated within non-induced cells. This complicates interpretation of the $K_{m}$, but suggests that uptake of naphthalene may not limit the rate of reaction. It seems probable, therefore, that the rate of disappearance of naphthalene gives a proper measure of the activity of naphthalene oxygenase, unless this reaction is tightly coupled to a subsequent rate-limiting step, in which case the measured activity would represent a minimal value. An additional uncertainty in reaction rates determined by this method arises because salicylate initially accumulates at a linear rate but begins to disappear after longer incubations. A comparison of the rate of decrease of absorbance at $276 \mathrm{~nm}$ with the rate of increase in absorbance at $295 \mathrm{~nm}$ effected by Pseudomonas NCIB98 I 6 induced with salicylate indicated that salicylate accumulated at about $53 \%$ of the rate at which naphthalene disappeared. Consequently, the extinction coefficient of naphthalene at $276 \mathrm{~nm}$ ought to be corrected for the presence of salicylate, of which the extinction coefficient at $276 \mathrm{~nm}$ is $1 \cdot 44 \mathrm{mmol}^{-1} \mathrm{~cm}^{-1}$. Neglect of this correction leads to an underestimation of the reaction rate by about $17 \%$. The magnitude of this correction should be assessed in each individual case. For example, after the induction of Pseudomonas NCIB98I6 with gratuitous inducers, when salicylate hydroxylase activity is lower than after induction with salicylate (Table 1), the rate of accumulation of salicylate is greater, and failure to correct the extinction coefficient leads to a greater underestimation of the reaction rate. This correction has not been applied to the results presented in Table I, and the activities presented are therefore minimum values.

Table I gives the levels of naphthalene oxygenase, salicylate hydroxylase, catechol 1,2oxygenase and catechol 2,3-oxygenase in Pseudomonas NCIB9816 grown under different conditions. Naphthalene oxygenase was induced during growth on naphthalene and 


\section{Table I. The specific activities of certain enzymes in Pseudomonas species NCIB9816 grown in the presence of different compounds}

Cells were grown on the given carbon source and harvested in the exponential phase, or grown on succinate in which case the second compound was added early in the exponential phase $\left(E_{\text {lem. }}^{660}\right.$. about $O . I$ ) and cells were harvested after doubling twice. Concentrations are given in brackets. Enzyme activities were determined with whole cells (naphthalene oxygenase) and extracts (other enzymes), and calculated specific activites are based on a unit weight of protein, in whole cells or extract as appropriate.

\section{Carbon source or effector added}

Succinate $(8.5 \mathrm{~mm})$

Salicylate (3.5 mM)

Naphthalene $(0 \cdot I \%, w / v)$

Catechol ( $9.0 \mathrm{~mm})$

Succinate $(8.5 \mathrm{~mm})+$ salicylate $(3.5 \mathrm{~mm})$

Succinate $(8.5 \mathrm{~mm})+2$-aminobenzoate (0.35 mM)

Succinate $(8 \cdot 5 \mathrm{~mm})+2$-hydroxybenzyl alcohol (3.5 mM)

Succinate $(8.5 \mathrm{~mm})+$ catechol $(3.5 \mathrm{~mm})$
Specific activity ( $\mu \mathrm{mol} / \mathrm{min} / \mathrm{mg}$ protein)

$\begin{array}{cccc}\begin{array}{c}\text { Naphthalene } \\ \text { oxygenase }\end{array} & \begin{array}{c}\text { Salicylate } \\ \text { hydroxylase }\end{array} & \begin{array}{c}\text { Catechol } \\ \text { r,2-oxygenase }\end{array} & \begin{array}{c}\text { Catechol } \\ \text { 2,3-oxygenase }\end{array} \\ 0.016 & 0.003 & 0.003 & 0.059 \\ 0.280 & 0.340 & 0.340 & 0.025 \\ 0.339 & 0.395 & 0.277 & 0.029 \\ 0.013 & -- & - & - \\ 0.101 & 0.452 & 0.363 & 0.015 \\ 0.142 & 0.040 & 0.017 & 0.032 \\ 0.146 & 0.057 & 0.007 & 0.056 \\ 0.017 & -- & 0.440 & 0.030\end{array}$

salicylate, but not after growth on catechol. This suggested that salicylate, the immediate precursor of catechol, might be the inducer of naphthalene oxygenase; however, the possibility remained that the inducer might be a metabolite of catechol if different catechol-degrading pathways were present, depending on whether catechol were added in large concentrations or formed only in limiting quantities as an intermediate in salicylate degradation. This is indeed the situation in certain pseudomonads (Davies \& Evans, I964; Chakrabarty, 1972). The levels of the two catechol oxidases after the addition of catechol to cultures growing on succinate were, however, similar to those observed when salicylate was added, and this reduces the probability that the inducer of naphthalene oxygenase is a metabolite of catechol. It does not exclude the possibility entirely, because the presence of the first enzyme of a pathway does not necessarily mean that all enzymes, and consequently all substrate intermediates, are present. In this context the question arises as to which pathway is utilized for catechol degradation in Pseudomonas NCIB98 16 . Our results are in accord with those of Evans, Fernley \& Griffiths (I965), who stated that catechol 2,3-oxygenase is a constitutive enzyme, but the levels of the enzyme are much lower than the induced levels of catechol I,2-oxygenase (Table 1).

To check the validity of the measurements of enzyme levels in extracts of Pseudomonas NCIB9816, it was shown that the activities of catechol 2,3-oxygenase, determined as the rates of accumulation of 2-hydroxymuconic semialdehyde, were neither limited by the presence of an enzyme competing for the same substrate (catechol I,2-oxygenase) nor limited by the destruction of 2-hydroxymuconic semialdehyde. Catechol 2,3-oxygenase in extracts of induced cells of Pseudomonas ATCCI 7483 was not inhibited in the presence of extracts of Pseudomonas NClB98 16 grown on succinate and induced with salicylate. 2-Hydroxymuconic semialdehyde, prepared by a method similar to that of Feist \& Hegeman (1969) using an extract of salicylate-induced cells of Pseudomonas ATCCI 7483 to effect oxidation of catechol, was not degraded by fresh cell extracts of induced or non-induced Pseudomonas NCIB98I 6 under the conditions used to measure catechol 2,3-oxygenase.

Confirmation of the proposed role of salicylate was sought by examining the ability of 


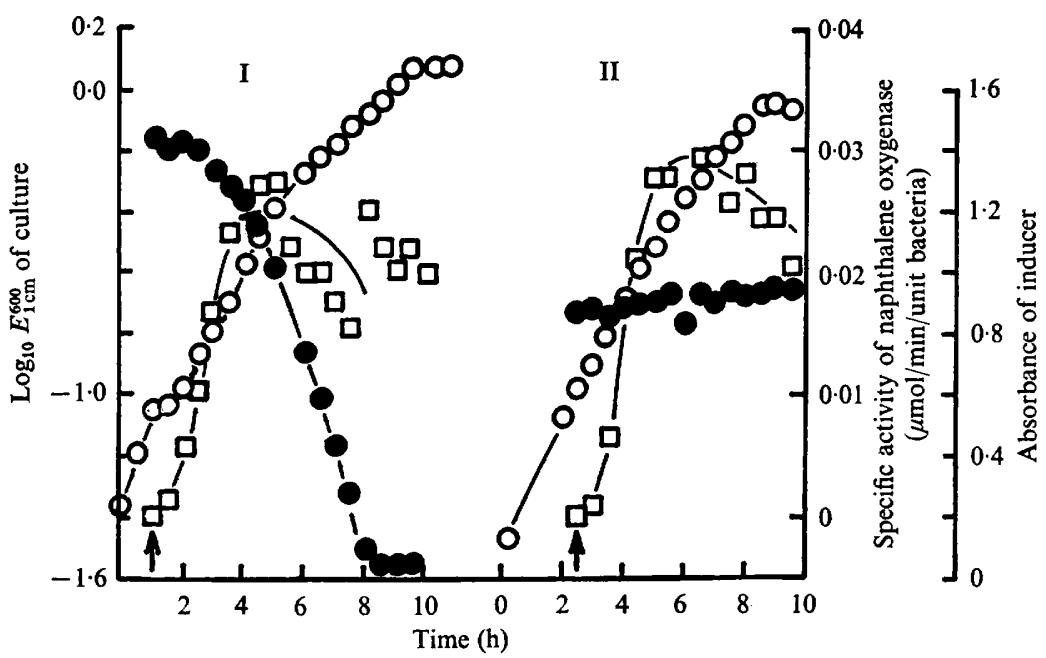

Fig. I. Induction of naphthalene oxygenase by $3.3 \mathrm{~mm}$-salicylate (1) and $0.32 \mathrm{~mm}$-2-aminobenzoate (II) in cultures of Pseudomonas NCIB9816 growing on succinate. The $E_{1 \mathrm{~cm}}^{600}(O)$ of salicylate was measured at $295 \mathrm{~nm}$ after eightfold dilution, whereas that of 2 -aminobenzoate was measured without dilution at $309 \mathrm{~nm}$. In the latter case the small significant rise in absorbance was consistent with the increase in the extinction coefficient as the $\mathrm{pH}$ rose from 6.8 to $7 \cdot 2$ during the course of the experiment. The specific activity of naphthalene oxygenase ( $\square$ ) was measured as described in the text; unit bacteria is defined as that quantity in $\mathrm{I} \mathrm{ml}$ of suspension with $E_{1 \mathrm{~cm}}^{600}=1 \cdot 0.0, \log _{10} E_{1 \mathrm{~cm}}^{600}$ of the culture. The arrow indicates time of addition of inducer.

compounds structurally similar to salicylate to induce naphthalene oxygenase gratuitously. The following compounds did not induce naphthalene oxygenase when added to cultures of Pseudomonas NCIB98I6 growing on succinate: 2'-hydroxyacetophenone, I,2-dimethoxybenzene, methyl salicylate, 3,5-dichlorosalicylate, 2-nitrobenzoic acid and 3-nitrosalicylic acid. $O$-Acetylsalicylate did induce naphthalene oxygenase, but was itself metabolized. 2-Hydroxybenzyl alcohol ( $3.5 \mathrm{~mm})$ and 2-aminobenzoic acid $(0.35 \mathrm{~mm})$ induced naphthalene oxygenase when added to cultures growing exponentially on succinate, and the concentration of these compounds, determined spectrophotometrically in the residual supernatant, remained unchanged throughout the exponential phase and into the stationary phase of growth (Fig. 1). 2-Hydroxybenzyl alcohol (3.5 mM) did not inhibit growth, whereas $0.35 \mathrm{~mm}$ 2-aminobenzoate sometimes caused about the same transient inhibition of growth as $3.5 \mathrm{~mm}$ salicylate. Pseudomonas NCIB98I 6 does slowly adapt to the gratuitous inducers, however, and can utilize them as sole carbon and energy sources after a prolonged lag period ( $48 \mathrm{~h}$ ). The gratuitous induction of naphthalene oxygenase by compounds structurally similar to salicylate supports the view that salicylate is the natural inducer of naphthalene oxygenase. The possibility that a precursor of salicylate is the inducer of naphthalene oxygenase is more difficult to exclude. Although the NAD-dependent oxidation of salicylaldehyde to salicylate (Davies \& Evans, 1964) would be expected to be associated with a large negative standard free-energy change at $\mathrm{pH} 7$, reversal cannot be excluded and the gratuitous inducers could well function as analogues of salicylaldehyde.

Other strains of pseudomonads growing on succinate also produced naphthalene oxygenase when salicylate was added to their cultures. These were NCIB8858, NCIB8859, NCIB8860, ATCCI7483, ATCCI7484, NI, N3 and N4. Other strains (NCIB9427, ATCCI748I, ATCC 17482 and ATCC17485) grew poorly in minimal medium containing naphthalene, and we could not demonstrate the presence of naphthalene oxygenase or its induction. 
It has been reported recently that in Pseudomonas the genes specifying the entire salicylate degradative pathway are plasmid-borne (Chakrabarty, 1972), and that the genes specifying the enzymes for naphthalene degradation as far as, and including, catechol oxidase may be plasmid-bourne in certain strains (Dunn \& Gunsalus, 1973). This situation has not been examined with the strains used in the present work. It was noted, however, that washed cells that had been grown on succinate and induced with salicylate, 2-hydroxybenzyl alcohol, or 2-aminobenzoic acid, degraded naphthalene with the concomitant appearance of salicylate. This was identified in extracts by its absorption spectrum (absorption maximum at $295 \mathrm{~nm}$ ) and chromatographic properties $\left(R_{F^{\prime}} 0.62\right)$ which were identical with those of authentic salicylic acid. The initial molar ratio of salicylate production to naphthalene disappearance effected by cells induced with either 2-hydroxybenzyl alcohol or 2-aminobenzoate was 0.8 . This observation implies that all enzymes leading to salicylate are induced en bloc, and the genes specifying them may therefore constitute a single operon. It seems unlikely that this extends to salicylate hydroxylase, for the ratio of naphthalene oxygenase to salicylate hydroxylase was lower when salicylate was the inducer than when gratuitous inducers were employed. Since the gratuitous inducers also induce salicylate hydroxylase, they (and perhaps salicylate also) may play a dual role as inducers.

We thank the Memorial University of Newfoundland for a postgraduate fellowship (to K.M.S.), and the N.R.C. for a research grant (to E.A.B.).

\section{REFERENCES}

Azoulay, E. (1966). Régulation de la biosynthèse et de l'activité des catéchol-oxygénases chez Pseudomonas. Bulletin de la Société française de physiologie végétale I2, I I I-I 21.

Catterall, F. A., Murray, K. \& Williams, P. A. (1971). The configuration of the I,2-dihydroxy-I,2dihydronaphthalene formed in the bacterial metabolism of naphthalene. Biochimica et biophysica acta 237, 36I-364.

Catterall, F. A. \& Williams, P. A. (I97I). Some properties of the naphthalene oxygenase from Pseudomonas sp. NCIB9816. Journal of General Microbiology 67, I1 7-124.

Chakrabarty, A. M. (1972). Genetic basis of the biodegradation of salicylate in Pseudomonas. Journal of Bacteriology II2, 815-823.

Davies, J. I. \& Evans, W. C. (I962). Ring fission of the naphthalene nucleus by certain soil pseudomonads. Biochemical Journal 85, 2 I P.

Davies, J. I. \& Evans, W. C. (I964). Oxidative metabolism of naphthalene by soil pseudomonads. The ring fission mechanism. Biochemical Journal 9I, 25I-26r.

DunN, N. W. \& Gunsalus, I. C. (1973). Transmissible plasmid coding early enzymes of naphthalene oxidation in Pseudomonas putida. Journal of Bacteriology 114, 974-979.

Evans, W. C., Fernley, H. N. \& Griffiths, E. (1965). Oxidative metabolism of phenanthrene and anthracene by soil pseudomonads. The ring-fission mechanism. Biochemical Journal 95, 819-831.

Feist, C. F. \& Hegeman, G. D. (1969). Phenol and benzoate metabolism by Pseudomonas putida: regulation of tangential pathways. Journal of Bacteriology roo, 869-877.

Hegeman, G. D. (1966). Synthesis of the enzymes of the mandelate pathway by Pseudomonas putida. I. Synthesis of enzymes of the wild type. Journal of Bacteriology 9I, I I40-I I 54.

Jerina, D. M., Daly, J. W., JefFrey, A. M. \& Gibson, D. T. (I97I). cis-I,2-Dihydroxy-I,2-dihydronaphthalene: a bacterial metabolite of naphthalene. Archives of Biochemistry and Biophysics 142, 394-396.

Lowry, O. H., Rosebrough, N. J., Farr, A. L. \& Randall, R. J. (1951). Protein measurement with the Folin phenol reagent. Journal of Biological Chemistry 193, 265-275.

SKerman, V. B. D. (1967). A Guide to the Identification of the Genera of Bacteria with Methods and Digests of Generic Characteristics. 2nd edition. Baltimore: Williams \& Wilkins. 